\title{
Optimal usage of saline and non saline irrigation water; A policy tool
}

\author{
Arye Sadeh \\ Technology Management Department, \\ Center for Technological Education Holon \\ P.O.B. 305, Holon, Israel. e-mail: sadeh@barley.cteh.ac.il
}

\section{INTRODUCTION}

The shortage of good fresh water for agriculture has encouraged farmers to use water with differential quality. The usage of low quality water has three levels of consequences: immediate, intermediate and long run effects. The immediate consequences are on yield levels, intermediate impacts are reversible damages to soils, and the long run effects are on water aquifers and considerable damages to soils. Information about the economic value of using low quality water is of interest when the supply of water is limited and should be allocated among many farmers (Yaron and Voet, 1983).

This study focuses on a constrained optimization model to evaluate the immediate and the intermediate economic values of using differential water qualities for agricultural purposes, under conditions of water shortage.

\section{BIO-ECONOMIC SYSTEM}

The general problem is set of two sub-models, a biological model and an economic model for an individual decision maker. The biological model consists of two systems: a water-soil system and a soil-plant system.

\subsection{The water-soil system}

The soil in the root depth zone is the storage for water and salt. At any point of time there is a balance of water and balance of salt in the soil (Bresler et al., 1982). Water and salt are introduced to the soil via irrigation or rainfall. Water can be evaporated from the soil to the atmosphere directly, or to be transpirated via plants. Higher rates of transpiration are associated with better plants. On the other hand water can be percolated downward from the soil root zone, as the amount of water exceeds the soil ability to hold water.

Salt is introduced to soil via irrigation and can be leached downward via percolated 
water. Farmers may also reduce soil salinity rate by leaching salt below the root depth, using excess of low rate saline irrigation water.

It is assumed that mixture of saline and non saline water can be produced and applied to crops; therefore, infinite number of combinations of amount of water and salt concentrates are considered for irrigation.

\subsection{The soil-plant system}

Plants have to overcome a combination of matrix and osmotic pressures in their effort to absorb water from the soil. More water in the root depth results in a small matrix pressure. At the same time, a high soil salinity level results in a high osmotic pressure. That is, there is a room for substitution between water content and the rate of salinity in the soil during the growth period. The response of crop to available water is determined (Letey et al., 1986) as well as the response of crops to soil salinity (Maas and Hoffman, 1977). The existence of salt in soil water results in less transpiration. Consequently, more water stay in the soil, the matrix pressure decrease, and a feedback of the salt on crops' growth is revealed.

A seasonal simulation model is developed in order to describe the water-soil sub-system and the soil-plant sub-system. The model simulates the actual yield and soil salinity and soil's water content. The state variables are soil salinity and soil's water content, the output variables are yield, water and salt drainage below the root zone, and water transpirated to the atmosphere. The input variables are amount of water and the salt concentrate. The equations of motion are the responses of crops to water and salt and the dynamics of salt and water in the depth root zone. The initial values of soil salinity and soil water content should be provided along with other parameters of the equations of motions.

The results from the simulation model were incorporated into an economic decision model. A quadratic approximation of yield with respect to relevant ranges of initial values and inputs is used based on simulation's results.

\section{ECONOMIC MODEL FOR AN INDIVIDUAL DECISION MAKER}

Having the responses of different crops to soil salinity and water, decision maker has to allocate the lands by their initial salinity, and water by their salt content, among crops. The decision maker wants to maximize profits and cannot affect the markets of inputs or outputs. This is a mathematical programming problem with non linear objective and constraints.

\subsection{Formulation of the model}

A decision maker has soils of different types, irrigation water of different qualities, and a variety of crops as production alternatives.

$L$ types of soils. They differ by their initial soil salinity at the beginning of a growing season.

$N$ different crops (production technologies)

$M$ sources of water differ by their salt concentration and unit cost per cube.

$k=1,2, \ldots, L ; k$ is index of soil type 
$i=1,2, \ldots, N ; i$ is index of crop

$j=1,2, \ldots, M ; j$ is index of source of water.

$W_{i j k}$ is the amount of water from source $j$ for crop $i$ on soil type $k$

$Y_{i k}$ is the yield from one dunam of crop $i$ on soil type $k$

$C_{j}$ is the unit cost of water from source $j$.

$P_{i}$ is the unit price of $1000 \mathrm{~kg}$ yield of crop $i$

$X_{i k}$ is the number of dunams allocated for crop $i$ of soil type $k$

$T C_{i k}$ is the total Costs, except water costs, associated with growing crop $i$ on soil type $k$.

These are fixed costs or variable costs that are not functions of yield's levels $\left(Y_{i k}\right)$.

Note the followings:

(1) The total amount of water applied to crop $i$ on soil type $k$ is

$W_{i k}=\sum_{j=1}^{M} W_{i j k}$

(2) The concentration of salt is therefore

$S_{i k}=\frac{\sum_{j=1}^{M} W_{i j k} \cdot S_{j}}{W_{i k}}$

The decision variables are $X_{i k}$ and $W_{i j k}$ for all $i, j$ and $k$.

The objective function is to maximize profits with respect to all $X_{i k}$ and $W_{i j k}$ :

$\max _{X_{i k}, W_{i j k}}\left[\sum_{i} \sum_{k}\left(P_{i} \cdot X_{i k} \cdot Y_{i k}-\sum_{j} C_{j} W_{i j k}-T C_{i k}\right)\right]$

subject to:

Production relationships:

$Y_{i k}=Y_{i k}\left(W_{i k}, S_{i k}, S S_{i k}\right)$

$W_{i k}=\sum_{j=1}^{M} W_{i j k}$

$S_{i k}=\frac{\sum_{j=1}^{M} W_{i j k} \cdot S_{j}}{W_{i k}}$

$S S_{i k}=f\left(S S_{k}, W_{i k}, S_{i k}\right)$

the relevant average soil salinity level, as a function of initial soil salinity crop characteristics and water and salt irrigated to the soil. 
Sources constrains

Water constrains by type of water

$\sum_{i} \sum_{k} X_{i k} \cdot W_{i j k}<Q_{j}$

The summations are for a given source of water $j$.

Land constrains

$\sum_{i} X_{i k}<\mathrm{LAND}_{k}$

The summation is for a given land of type $k$.

Other managerial constraints e.g. labor constraints could be included.

Note the differences: $S S_{i k}$ is the average soil salinity when producing crop $i$ on soil type $k$

$S S_{k}$ is the initial soil salinity of soil type $k$

$S_{i k}$ is the salt concentrate of water applied to crop $i$ on soil type $k$.

Number of dunams of each soil type $k$ is an input, while $S S_{i k}$ is solved internally in the simulation model and $S_{i k}$ is a result of mixing (inputs) water of different quality.

\section{APPLICATION AND RESULTS}

The simulation model was run for cotton and tomatoes in southwest Israel. This is an area with limited rainfall and water is carried to this area from the northern part of Israel. The base scenario includes 4000 dunams with 1.4 million cube of good water. The soil's characteristics and crops' characteristics are adopted from other published experiments' results (Shalhevet, 1994), (Vinten et al., 1991). The production alternatives are cotton and tomatoes. Profits from one ton of cotton and tomatoes are $\$ 650$ and $\$ 46$, respectively. (excluding water's costs). Unit costs of one meter cube of good water and saline water are 15 cents and 4 cents, respectively.

\subsection{Base run}

All 4000 dunams and 1.4 million cube of good water are allocated for cropping tomatoes. The yield is 6.175 tons per dunam from 350 cube of good water. The dual costs (shadow price) of soil and water are $\$ 36$ and $\$ 0.7$, respectively. The objective value is $\$ 1,091,018$.

\subsection{Second scenario}

Half of the 1.4 Million water quote of the decision maker is substituted with saline water $(\mathrm{EC}=5 \mathrm{dsm} / \mathrm{m})$, with unit costs of 4 cents per one cube.

1796 dunams with 390 cube per dunam of good water are allocated for tomatoes. Cotton is grown on 2204 dunams with 327 cube/dunam saline water. The yield levels are 6.8 and $0.4 \mathrm{ton} /$ dunam for tomatoes and cotton, respectively. The objective value is $\$ 1,076,053$ 
with $\$ 0.63$ and $\$ 0.61$ dual costs for good and saline water, respectively. The dual costs for soil is $\$ 50$.

\subsection{Third scenario}

The initial soil salinity in both base and second scenarios is $2 \mathrm{dsm} / \mathrm{m}$. This is the electrical conductivity of the water content in the soil. For the third scenario the initial salinity is set to $3 \mathrm{dsm} / \mathrm{m}$.

Tomatoes are grown on 1740 dunams with 402 cube of good water per dunam yielding 6.77 ton/dunam. On the other hand, cotton is grown on 2260 dunams with 310 cube of saline water, yielding 0.38 ton/dunam. The objective value is $\$ 1,051,126$ and the dual costs of soil is $\$ 46.6$. The dual costs of good and saline water are $\$ 0.62$ and $\$ 0.61$, respectively.

\subsection{Fourth scenario}

The soil salinity of 2000 dunams is set to $2 \mathrm{dsm} / \mathrm{m}$ and for the other 2000 dunams it is set to $3 \mathrm{dsm} / \mathrm{m}$. All other parameters are the same as in scenario 3 .

The 2000 saline dunams $(3 \mathrm{dsm} / \mathrm{m}$ ) are devoted for cotton along with 315 cube of saline water per dunam. the cotton yield is 0.4 ton/dunam. The 2000 dunams with 2 $\mathrm{dsm} / \mathrm{m}$ salinity level are allocated to cotton (220 dunams) and tomatoes (1780). About $393 \mathrm{cub} /$ dunam of good water are allocated to tomato, yielding $6.84 \mathrm{ton} / \mathrm{dunam}$. Only 321 of saline water are allocated for each dunam of cotton yielding 0.4 ton/dunam of cotton. The objective value is $\$ 1,069,605$. The dual costs of $2 \mathrm{dsm} / \mathrm{m}$ soil and of $3 \mathrm{dsm} / \mathrm{m}$ soil are $\$ 51$ and $\$ 47.7$ respectively. The dual costs of good and saline water are $\$ 0.63$ and $\$ 0.61$ respectively.

\subsection{Policy consequences}

The results of the four scenarios can be used to evaluate variables of interest. For example, the difference between the objective values of the base scenario and the second scenario $(\$ 14,965)$ is a compensation for the farmer for using saline water rather than good water. The difference between the third and the second scenario $(\$ 24,927)$ is the cost of having a salty soil. This implies that a farmer should be compensated for having salty soils due to a usage of saline water.

Farmers considering two management strategies, using saline water all over their soils or using saline water in particular fields over the years. The first alternative will yield low level saline soils, yet all soils will be somehow salty. The second alternative means that certain soils will be useful for crops that are tolerated to soil, e.g. cotton. The difference between the second and the fourth scenario is the costs of having half of the soils salty ( 3 $\mathrm{dsm} / \mathrm{m}$ ). That is, the previous year's irrigation policy came out with final salty soils.

The dual costs (shadow prices) of each resource constraint are very useful for marginal economic analysis. For example, the difference in shadow prices of saline and non saline, is much higher than those in the third scenario. This implies farmers cannot exercise the economic advantage of tomatoes over cotton. The advantage was revealed in the base run. Rather, the cotton, a tolerant crop toward saline water is a substitution for tomatoes. The high dual cost of water in the base run compared with other run's results, implies that farmers would like to have more good water even if the unit costs increase. 


\subsection{Recommendations for future research}

A beneficial extension of the model will be by incorporating the short run model into a long run framework. This includes the feedback impact of having saline lands at the beginning of each growing season on a general long run objective function. There is a need to incorporate the impact of rainfall and the uncertainty consequences resulted from rainfall on decision making processes.

\section{REFERENCES}

Bresler, E., McNeal, B.L. and Carter, D.L. (1982) Saline and Sodic Soils. Springer-Verlag, Berlin.

Letey, J. and Dinar, A. (1986) Simulated Crop-Water Production Functions for Several Crops When Irrigated with Saline Water. Hilgardia, 54, 1-32.

Maas, E.V. and Hoffman, G.J. (1977) Crop Salt Tolerance Current Assessment. J. Irrig. and Drainage Div., ASCE, Vol 103 No. IR2, proc. Paper 12993, 115-34.

Shalhevet, J. (1994) Using Water of Marginal Quality for Crop Production: Major Issues. Agricultural Water Management, 25, 233-69.

Vinten, A.J., Frenkel, A., Shalhevet, J. and Elston, D.A. (1991) Calibration and Validation of a Modified Steady State Model for Crop Response to Saline Water Irrigation Under Conditions of Transient Root Zone Salinity. J. Contam. Hydrol. 7, 123-45.

Yaron, D. and Voet, H. (1983) Optimal Irrigation with Dual Quality (Salinity) Water Supply and the Value of Information, in Agribusiness Planning and Decision Models (eds. G. Schiefer and C.H. Hanf), Elsevier, Amsterdam.

The author wish to thank the office of the Israeli Water Commissioner, the Committee on Saline Water Evaluation and ARO for their help. 